\title{
Biopolymer-based scaffolds for corneal stromal regeneration: A review
}

\author{
Hamed Nosrati ${ }^{1}, \mathrm{~A}-\mathrm{F}$, Korosh Ashrafi-Dehkordi ${ }^{2, D-F}$, Zohreh Alizadeh ${ }^{3,4, E, F}$, Samira Sanami ${ }^{5}, \mathrm{~B}, \mathrm{D}, \mathrm{F}$, , Mehdi Banitalebi-Dehkordi2,D-F \\ ${ }^{1}$ Department of Tissue Engineering and Applied Cell Sciences, School of Advanced Technologies, Shahrekord University of Medical Sciences, Shahrekord, Iran \\ 2 Department of Molecular Medicine, School of Advanced Technologies, Shahrekord University of Medical Sciences, Shahrekord, Iran \\ ${ }^{3}$ Department of Anatomy, School of Medicine, Hamadan University of Medical Sciences, Hamadan, Iran \\ ${ }^{4}$ Endometrium and Endometriosis Research Center, Hamadan University of Medical Sciences, Hamadan, Iran \\ ${ }^{5}$ Department of Medical Biotechnology, School of Advanced Technologies, Shahrekord University of Medical Sciences, Shahrekord, Iran \\ A - research concept and design; $\mathrm{B}$ - collection and/or assembly of data; C - data analysis and interpretation; \\ $D$ - writing the article; $E$ - critical revision of the article; $F$ - final approval of the article
}

\section{Address for correspondence \\ Hamed Nosrati}

E-mail: hamednosratibio@gmail.com

\section{Funding sources}

None declared

\section{Conflict of interest}

None declared

Received on July 31, 2020

Reviewed on September 3, 2020

Accepted on September 18, 2020

\begin{abstract}
The stroma is one of the 5 layers of the cornea that comprises more than 90\% of the corneal thickness, and is the most important layer for the transparency of cornea and refractive function critical for vision. Any significant damage to this layer may lead to corneal blindness. Corneal blindness refers to loss of vision or blindness caused by corneal diseases or damage, which is the $4^{\text {th }}$ most common cause of blindness worldwide. Different approaches are used to treat these patients. Severe corneal damage is traditionally treated by transplantation of a donor cornea or implantation of an artificial cornea. Other alternative approaches, such as cell/stem cell therapy, drug/gene delivery and tissue engineering, are currently promising in the regeneration of damaged cornea. The aim of tissue engineering is to functionally repair and regenerate damaged cornea using scaffolds with or without cells and growth factors. Among the different types of scaffolds, polymer-based scaffolds have shown great potential for corneal stromal regeneration. In this paper, the most recent findings of corneal stromal tissue engineering are reviewed.
\end{abstract}

Key words: biopolymer, tissue engineering, scaffold, corneal stroma

Cite as

Nosrati H, Ashrafi-Dehkordi K, Alizadeh Z, Sanami S, Banitalebi-Dehkordi M. Biopolymer-based scaffolds for corneal stromal regeneration: A review. Polim Med. 2020;50(2):57-64. doi:10.17219/pim/127653

DOI

10.17219/pim/127653

\section{Copyright}

(C) 2020 by Wroclaw Medical University This is an article distributed under the terms of the Creative Commons Attribution 3.0 Unported (CC BY 3.0) (https://creativecommons.org/licenses/by/3.0/) 


\section{Introduction}

The outer layer of the eye consists of sclera and cornea. The cornea plays an essential role in the ocular light pathway and consists of 5 distinct layers (from outside to inside): the epithelium, Bowman's membrane, stroma, Descemet's membrane, and endothelium. Injuries leading to scarring and diseases such as keratoconus (cornea progressive thinning) and bullous keratopathy (an endothelial dysfunction which causes formations of small vesicles in the cornea) can cause blindness and visual impairment due to corneal damage. ${ }^{1}$ Corneal blindness is a widespread problem that is the $4^{\text {th }}$ cause of blindness in the world, with more than 10 million people having bilateral blindness, while only about 185,000 corneal transplants are performed annually worldwide. ${ }^{2,3}$ Treatment of corneal blindness imposes considerable economic pressure on the medical system and patients. The management of the pathological conditions seems to be an important issue in reducing the economic pressure and improving patients' quality of life. ${ }^{4,5}$

Corneal transplantation is still the most frequent type of transplant in the world, which can improve the visual function in case of severe corneal damage. Transplanted allograft tissue poses the risk of stimulus-immune responses that may cause transplant rejection; there is also a possibility of transmitting certain diseases from the grafted tissue. ${ }^{6}$ In addition, transplantation of an organ or a tissue may be a process with numerous cultural, ethical and legal barriers. ${ }^{7}$ To address these issues, many scientists have tried to replace the cornea with a variety of alternative solutions (Fig. 1).

Corneal replacements include 2 categories: keratoprosthesis and tissue-engineered structures. Keratoprosthesis or corneal prosthesis is a surgical alternative to donor transplantation. Various commercially available corneal prostheses, such as Boston KPro and osteo-odonto-keratoprosthesis (OOKP), are used clinically with a different rate of success. ${ }^{8}$ Although the material and design of the prostheses vary, poly(methyl methacrylate) (PMMA) is considered as a basic primary material. ${ }^{9}$ Retinal detachment, calcification, glaucoma, corneal melting, prosthesis extru- sion, and some other complications are reported as a result of using these keratoprostheses. ${ }^{10}$

Researchers have also developed cell-/stem cell-based methods to overcome the limitations of previous approaches. Cell therapy methods are used to regenerate the endothelium and epithelium layers, but rarely for stromal regeneration. Due to the limitations of the current methods, alternative regenerative approaches are required. In corneal tissue engineering, different engineered structures are used to form corneal substitutes. Biomaterials used for corneal regeneration should have several critical features: high transparency, biocompatibility and moisture conservation. ${ }^{11}$ Suitable mechanical properties are essential factors of the cornea to protect its structure, morphology and normal functionality. ${ }^{12}$

In this review, we focus on the most recent available corneal stroma replacement approaches. While the corneal endothelium and the ocular surface have been a subject of interest in corneal investigations for several years, stromal regeneration has recently become the subject of equally studied research. This is because this layer is probably the most challenging of all 3 layers to repair, regenerate or replace. The complex structure of the stroma makes it very difficult to be engineered, and therefore a wide range of approaches (including polymer-based scaffolds) are being investigated in order to find an optimal stromal replacement. This paper provides a review of recent polymer-based scaffolds used for corneal stromal tissue engineering.

\section{Anatomy and histology of the cornea}

The cornea is a transparent connective tissue with no blood vessels that provides an optical interface. It protects the eye from infections and provides good mechanical support. The human cornea is $12-13 \mathrm{~mm}$ in diameter and $0.5 \mathrm{~mm}$ in thickness at its center. ${ }^{13}$ The 3 distinct cellular layers, including corneal epithelium (external layer), stroma and endothelium (internal layer), are separated by 2 acellular interfaces. Bowman's layer is between the stratified
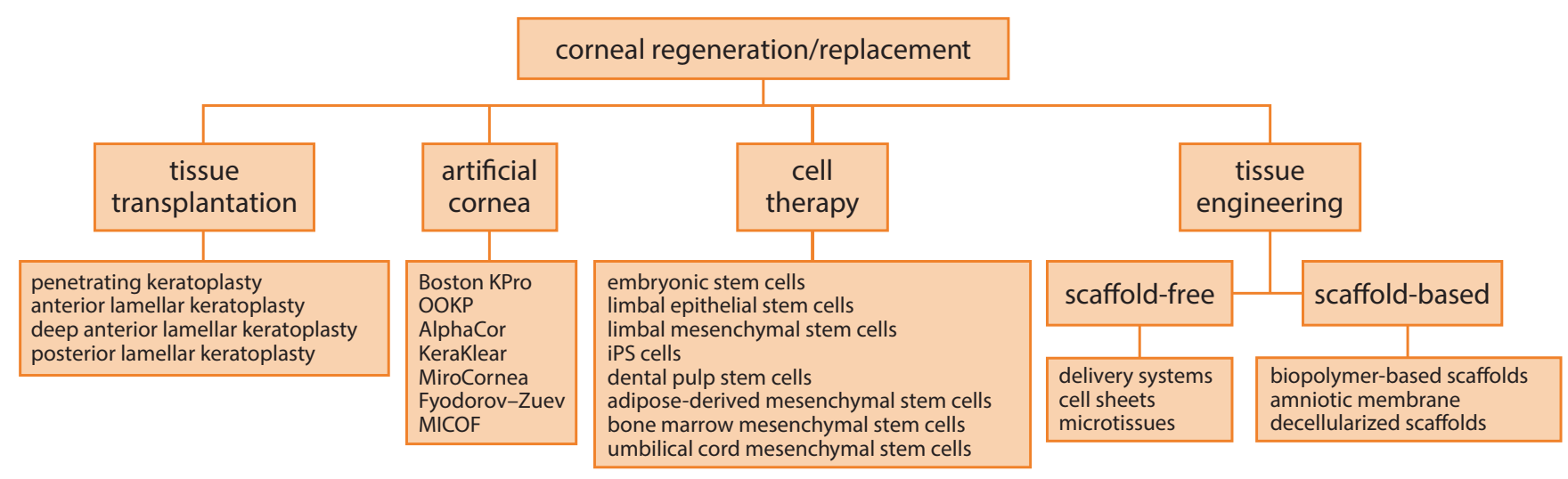

Fig. 1. Therapeutic strategies for corneal replacement/regeneration 
epithelium and the stromal layer. Descemet's membrane is the basal lamina of endothelium that separates it from the stromal layer. The cornea tissue is rich in collagen and contains a leucine-rich proteoglycan-like keratan sulfate. The corneal epithelium is a 4-6-layered non-keratinized stratified squamous tissue with 40-50 $\mu \mathrm{m}$ thickness, which is highly innervated. ${ }^{14,15}$ Tear film, which covers the outside of the epithelium, provides a smooth surface that can help light refraction. Moreover, it is anti-bacterial and necessary for the proliferation, repair and maintenance of epithelial homeostasis. ${ }^{16}$ Bowman's membrane is a condensed layer of collagen $15 \mu \mathrm{m}$ in thickness located posterior to the epithelium. It is also known as anterior limiting lamina. Bowman's membrane is one of the barriers regulating the transfer of molecules. Approximately $90 \%$ of the thickness of the cornea is attributed to the stromal layer, which consists of aligned collagen fibers (lamellae), and there are different collage types, such as collagens type I, V, XIV, XII, and VI. ${ }^{17}$ Decorin, lumican and keratocan are small leucine-rich proteoglycans that regulate hydration of the cornea and are also required for its transparency. ${ }^{13,18}$ The woven collagen bundles between adjacent lamellae provide mechanical strength needed to withstand shear stress by transferring stress between lamellae. In the embryonic period, keratocytes migrate from neural crest to the corneal stroma and locate between lamellae to produce the matrix components. ${ }^{19}$ A thick type VIII collagen-rich basement membrane is located posterior to the stroma named Descemet's membrane. The corneal endothelium layer anchors this membrane. The endothelium removes water from the stroma to maintain corneal transparency. ${ }^{20,21}$ The main functions of the cornea are determined as protection, transparency and maintaining optical properties. The stroma is a dense, non-vascularized tissue that contains organized collagen fibrils to protect tissue from tensile strength and shear stress (Fig. 2). Collagen fibers and endothelium function provide the transparency of the cornea, which determines optical properties. ${ }^{22}$

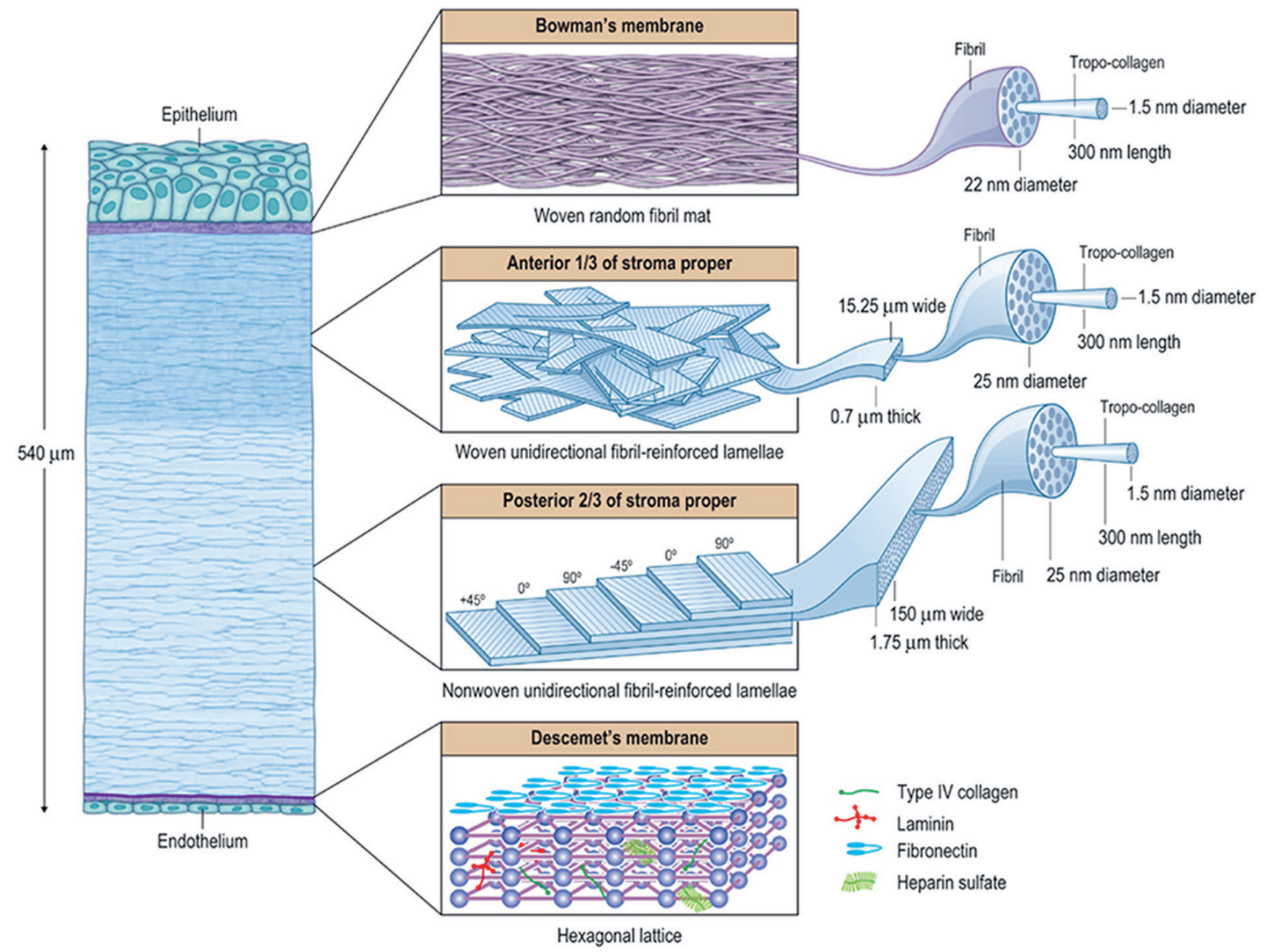

Fig. 2. The structure of cornea indicating that it is composed of 3 cellular layers separated by Descemet's membrane and Bowman's layer. The histology and molecular structures of the cornea are shown to help illustrate different interactions between the corneal tissue components. The anterior third of the corneal stroma is a lamellar interwoven fabric composed of unidirectionally fibril-reinforced lamellae. The posterior two-thirds of this tissue is a nonwoven, unidirectionally fibril-reinforced lamellae. This highly specialized structure brings strength and stiffness for corneal tissue. The unidirectional orientation of collagen fibrils in each lamella is critical, because this unique arrangement prevents fibril undulation and also maintains the mechanical properties of the cornea. Reprinted with permission from Elsevier ${ }^{22}$ 


\section{Tissue transplantation}

One of the current clinical approaches is to replace the full-thickness tissue through transplantation of a cornea during penetrating keratoplasty. These corneas are obtained from cadaveric donors. All 5 layers, including the epithelium (as the corneal surface), Bowman's membrane, stroma, Descemet's membrane, and endothelium, would be replaced after penetrating keratoplasty. Some remarkable changes in the functioning and morphology of the corneal surface were observed after this surgery. For example, after penetrating keratoplasty, the metabolism of the epithelial cells decreased in terms of oxygen absorption compared to the healthy eye. ${ }^{23,24}$

Anterior lamellar keratoplasty and deep anterior lamellar keratoplasty are also available transplantation techniques. In these surgeries, the host corneal endothelium and Descemet's membrane are left untouched. In the deep anterior lamellar keratoplasty, the corneal surface and the whole stroma are replaced, but in the anterior lamellar keratoplasty, a part of the patient's stroma is left intact. Both of these techniques are considered partial replacements of corneal tissue. The advantages of these methods compared to penetrating keratoplasty are that they are less invasive and also reduce endothelial damage, which prevents transplant rejection. ${ }^{25,26}$

Posterior lamellar keratoplasty is another technique to replace the corneal endothelium, Descemet's membrane and posterior part of the stroma. ${ }^{27}$ Transplantation of the corneal endothelium was first described by Melles et al. ${ }^{28}$ They called this technique posterior lamellar keratoplasty. This technique was then improved by Terry and Ousley, who renamed it deep lamellar endothelial keratoplasty. This surgery required manual lamellar dissections within the deep corneal stroma of both the donor and the recipient corneas. ${ }^{29}$ The next significant modification of posterior lamellar keratoplasty was Descemet's stripping endothelial keratoplasty. In this procedure, instead of performing a lamellar dissection, the patient's Descemet's membrane is peeled off using specially designed strippers. ${ }^{30}$ Compared with deep lamellar endothelial keratoplasty, Descemet's stripping endothelial keratoplasty is easier to perform, and stripping the Descemet's membrane leaves a very smooth recipient interface onto which the donor can be applied. This may lead to better visual results, but has also been implicated as a cause of early postoperative donor dislocations. ${ }^{27}$

Although all of these surgical techniques provide good chances for patients, there is still a significant limitation in the number of donors.

\section{Artificial corneas}

As the number of donors decreases, artificial alternatives need to be developed. Pellier de Quengsy used a bio-inert glass as a substitute of cornea for the first time in $1789 .{ }^{31}$ In 1953, Stone and Herbert showed that PMMA constructs were well-maintained in the eyes of rabbits for 24 months. ${ }^{32}$ Artificial PMMA-based keratoprostheses are now commercially available and used in clinical setting. A keratoprosthesis consists of 2 main parts: a cylindrically shaped optical part (core part) and a surrounding skirt (haptic part) which ensures tight connection to the ocular tissue. The keratoprosthesis should preferably be manufactured through mechanical shaping from one piece of polymer for long-term tight connection between the optic and haptic parts. The polymer should be hydrophobic to avoid interaction with eye medications and dimensional changes. The polymer should also be flexible to allow the skirt to follow the movement of the surrounding tissue and prevent local stress. Moreover, the polymer must be transparent and immunologically safe to be used in human eyes. Therefore, the consortium focuses on the evaluation of various acrylic polymers with a glass transition temperature around $10^{\circ} \mathrm{C}$. This allows mechanical shaping at low temperature and flexibility at the temperature of the human eye. ${ }^{10,33}$ Different materials are used as optic and haptic parts to produce various keratoprostheses (Table 1).

Boston KPro is likely to be the best-known keratoprosthesis made of PMMA as the optic part and titanium as the haptic part. ${ }^{34}$ Another example of the use of PMMA-based artificial corneas is in OOKP, which uses a piece of tooth as a supporting structure. Many complications such as glaucoma, retinal detachment, prosthesis extrusion, calcification, and corneal

Table 1. Haptic and optic parts of different keratoprostheses ${ }^{40-46}$

\begin{tabular}{|lccc|c|}
\multicolumn{1}{|c}{ Keratoprosthesis } & Type & Haptic part & Optic part \\
\hline Boston KPro & Hard KPro & titanium & PMMA \\
OOKP & Hard KPro & a piece of tooth & PMMA \\
Miro ${ }^{\circledR}$ Cornea & Hard KPro & hydrophobic acrylic polymer & hydrophobic acrylic polymer \\
KeraKlear ${ }^{\circledR}$ & Hard KPro & hydrophilic acrylic polymer & hydrophilic acrylic polymer \\
Fyodorov-Zuev KPro & Hard KPro & titanium & PMMA \\
MICOF & Hard KPro & titanium & P2 \\
AlphaCor & Soft KPro & poly(2-hydroxyethyl methacrylate) & 43 \\
Legeais BioKPro-III & Soft KPro & polytetrafluoroethylene & polyvinylpyrrolidone-coated polydimethylsiloxane & 44 \\
\hline
\end{tabular}

PMMA - poly(methyl methacrylate). 
melting have been reported after employing artificial corneas. ${ }^{35,36}$ Many of these complications arise from the hydrophobic nature of the rigid materials used in these constructs. Hydrogel-based skirt prostheses were used in patients with a history of corneal transplant rejection. ${ }^{37}$ Fyodorov-Zuev KPro, KeraKlear ${ }^{\circledR}$ and Miro ${ }^{\circledR}$ Cornea are other examples of keratoprostheses which are not widely used in clinics. Fyodorov-Zuev KPro is made of PMMA and titanium, and its properties are similar to the Boston KPro. Fyodorov-Zuev KPro is a common keratoprosthesis for cornea transplantation in Russia and China. KeraKlear ${ }^{\circledR}$ represents a flexible structure developed in the USA. Miro ${ }^{\circledR}$ Cornea has been developed in Germany. One of the main complications of the recent prostheses is the formation of retro-prosthetic membrane after transplantation. ${ }^{38,39}$

\section{Biopolymer-based scaffolds for corneal stromal tissue engineering}

The shortage of donors and insufficient application potential of the keratoprostheses have led to numerous research studies investigating the production of tissue-engineered epithelial, stromal and endothelial replacements. Corneal stromal regeneration is a challenge for scientists because it has a complicated structure, and also unique optical transparency and mechanical strength. Corneal stromal regeneration is one of the critical targets for researchers, because creating functional stroma is very important in the treatment of corneal dysfunctions, and obtaining a prosthesis with satisfying mechanical, chemical and morphological properties alike is one of the most challenging issues in corneal stroma tissue engineering. ${ }^{47}$ Nowadays, using biopolymer-based scaffolds is a promising approach that has attracted much attention from research teams and is focused on regenerative strategies using different biomaterials in combination with various cell types. Biocompatibility, transparency and strength are considered to be the most important factors for corneal scaffolds. In addition, scaffold-based approaches are focused on the fabrication of constructs that could mimic the microenvironment of the native tissue to support cell adhesion, migration, proliferation, and differentiation. ${ }^{48}$

The researchers have used synthetic polymers as a substrate for engineering corneal stroma because they have adjustable mechanical properties. ${ }^{49,50}$ Moreover, some of these scaffolds have the capacity of inducing the differentiation of human stromal stem cells into keratinocyte lineage. For example, poly(ester urethane) has been used as a scaffold in combination with stromal stem cells in order to differentiate these cells to the keratinocyte lineage. Despite the differentiation of the stem cells, there were some weaknesses in the optical properties of the scaffold. ${ }^{51}$ Synthetic and natural biopolymers could be blended to improve the biological and optical properties. ${ }^{48}$ For example, Ozcelik et al. showed that hydrogel films composed of collagen type I, chitosan, poly(L- and D-lactic acid), and poly(ethylene glycol) present excellent biological, optical and mechanical properties compared with synthetic materials alone. ${ }^{52}$ Collagen type I, as a natural biopolymer, has many advantages such as encapsulating living cells, especially in the natural human cornea. This biopolymer is one of the components of stroma, so using this biopolymer as a component of corneal scaffolds could play an important role in corneal stromal regeneration. ${ }^{53}$ Collagen type I hydrogels have some weaknesses in mechanical properties that could be partially eliminated by chemical cross-linkers. ${ }^{54-56}$ For aligning the arrangement of fibroblasts (similar to the arrangement of the stromal cells), it is possible to produce aligned nanofibers of type I collagen using the electrospinning method, although this reduces transparency. ${ }^{57}$

Silk fibroin has been widely used for a variety of tissue engineering and biomedical applications. Due to the biocompatibility and transparency of silk protein, silk fibroin-based scaffolds are also utilized for corneal stromal tissue engineering. ${ }^{58}$ Silk films with well-developed topography, chemical surface modification, degradation rate, and porosity could provide excellent optical, mechanical and biological properties. ${ }^{59,60}$ Such optimized silk films seeded with suitable cell types can provide a high potential to be used as a functional corneal tissue equivalent in clinical approaches. Lawrence et al. fabricated silk thin films to replicate corneal stromal tissue architecture. ${ }^{61}$ The films were surface-patterned to induce cell alignment. To improve nutrients diffusion and to enhance cell interactions, micropores were introduced into the thin films. Proliferation of corneal fibroblast and expression of corneal extracellular matrix (ECM) on the silk films demonstrated the biocompability of these films. Their optical and mechanical properties were also appropriate to support the corneal stromal functions.

A strategy to improve the biocompatibility of scaffolds is to coat or modify their surfaces. ${ }^{62,63}$ In this regard, Ma et al. fabricated PMMA hydrogels surface-modified with amines and then coated with ECM proteins such as collagen I and IV, fibronectin, and laminin. The hydrogels were then surgically implanted into bovine corneas. The results demonstrated that specific surface modifications promote biocompatibility of the hydrogels. ${ }^{64}$ In another study, Gil et al. prepared arginine-glycine-aspartate (RGD)-coupled silk lamellar systems and studied the behavior of human corneal fibroblasts (HCF) in the presence of this system. ${ }^{65}$ They produced RGD-coupled, porous, patterned, transparent, and mechanically robust silk films. The effect of RGD-coupling on the proliferation, orientation, gene expression of HCF, and ECM organization was assessed. The results indicated that RGD surface modification improved proliferation, cell attachment, alignment, and expression of type I and V collagens, and also increased the expression of biglycan and decorin proteoglycans. They claimed that this system could mimic the structure of corneal stromal tissue and give a useful strategy to achieve an engineered human cornea. 
Table 2. Polymer-based scaffolds for corneal stromal regeneration

\begin{tabular}{|c|c|c|c|c|}
\hline Polymer-based scaffold & Cross-linker & Cell type & Clinical status & Reference \\
\hline $\begin{array}{l}\text { Gelatin/chondroitin sulfate porous } \\
\text { scaffold }\end{array}$ & carbodiimide & rabbit corneal keratocytes & in vitro & 66 \\
\hline $\begin{array}{l}\text { Poly(E-caprolactone)/silk fibroin } \\
\text { electrospun scaffold }\end{array}$ & - & human stromal keratocyte cells & in vitro & 67 \\
\hline $\begin{array}{l}\text { Poly( } \varepsilon \text {-caprolactone) electrospun } \\
\text { membrane }\end{array}$ & glutaraldehyde & human corneal stromal cells & in vitro & 68 \\
\hline Gelatin/chondroitin sulfate & $\mathrm{EDC} / \mathrm{NHS}$ & rabbit corneal keratocyte & in vitro & 69 \\
\hline $\begin{array}{l}\text { Poly( } \varepsilon \text {-caprolactone)-poly (ethylene } \\
\text { glycol)/GelMA hydrogel }\end{array}$ & - & limbal stromal stem cells & in vitro/in vivo (rat) & 70 \\
\hline Silk film & - & $\begin{array}{l}\text { human corneal stromal stem cells } \\
\text { and dorsal root ganglion neurons }\end{array}$ & in vitro & 71 \\
\hline Porous silk film & - & stromal cells & $\begin{array}{l}\text { in vitro/in vivo (multipocket } \\
\text { corneal stromal rabbit models) }\end{array}$ & 72 \\
\hline Multilayered silk films & - & $\begin{array}{l}\text { human corneal epithelial and } \\
\text { stromal stem cells }\end{array}$ & in vitro & 73 \\
\hline Compressed collagen & transglutaminase & corneal stromal cells & $\begin{array}{l}\text { in vitro/in vivo (female New } \\
\text { Zealand rabbits) }\end{array}$ & 74 \\
\hline Polyglycolic acid (PGA) fibers & - & rabbit corneal stromal cell & in vitro/in vivo (female rabbit) & 75 \\
\hline Multi-layered silk film & - & human corneal stromal stem cells & in vitro & 76 \\
\hline $\begin{array}{l}\text { Poly(ester urethane) urea fibrous } \\
\text { substrate }\end{array}$ & - & human corneal stromal stem cells & in vitro & 51 \\
\hline Gelatin/ascorbic acid cryogels & cryogelation technique & rabbit keratocyte & $\begin{array}{l}\text { in vitro/in vivo (alkali burn- } \\
\text { induced animal model) }\end{array}$ & 77 \\
\hline $\begin{array}{l}\text { Aligned poly(ester urethane) urea } \\
\text { substrate }\end{array}$ & - & $\begin{array}{l}\text { corneal stromal stem cells and } \\
\text { human corneal fibroblasts }\end{array}$ & in vitro & 78 \\
\hline Aligned polycaprolactone nanofibers & - & adult dental pulp cells & in vitro/in vivo (mouse) & 79 \\
\hline $\begin{array}{l}\text { Keratocyte spheroids fabricated } \\
\text { on chitosan coatings }\end{array}$ & - & rabbit stromal cells & $\begin{array}{l}\text { in vitro/in vivo (rabbit corneal } \\
\text { stromal defect model) }\end{array}$ & 80 \\
\hline Collagen type I gel & $\begin{array}{c}\text { bio-orthogonal strain- } \\
\text { promoted azide-alkyne } \\
\text { cycloaddition }\end{array}$ & keratocytes & in vitro & 81 \\
\hline Fibrin and fibrin-agarose scaffold & - & - & in vitro & 82 \\
\hline Magnetically aligned collagen fibrils & transglutaminase & keratocytes & in vitro & 83 \\
\hline Silk fibroin/chitosan scaffold & - & $\begin{array}{l}\text { primary rabbit corneal epithelial } \\
\text { cells and corneal stromal cells }\end{array}$ & $\begin{array}{l}\text { in vitro/in vivo (New Zealand } \\
\text { white rabbits) }\end{array}$ & 84 \\
\hline $\begin{array}{l}\text { Collagen/poly } \\
\text { (N-isopropylacrylamide) membrane }\end{array}$ & - & epithelial corneal cells & in vitro/in vivo (rabbit) & 85 \\
\hline Methacrylated gelatin & UV & human keratocytes & in vitro & 86 \\
\hline
\end{tabular}

EDC - N-ethyl-N'-(3-(dimethylamino)propyl)carbodiimide; NHS - N-hydroxysuccinimide.

The number of studies on corneal stromal regeneration has increased over the last decades. Table 2 contains recent approaches regarding corneal stromal regeneration, applying different biopolymer-based scaffolds.

\section{Conclusions and future perspectives}

Various approaches have been developed to replace or regenerate corneas. Each of the described methods has had important contributions to the rapidly evolving field of corneal stromal tissue engineering. The stroma is an important layer in the cornea, and its reconstruction in patients with corneal blindness means a huge improvement in their quality of life and also the possibility to restore their sight. While the ideal stromal replacement has not been established yet, there have been important efforts in the direction of a fully functional and biocompatible stromal transplant. Current corneal blindness treatment options, due to stromal opacities, remain limited to penetrating keratoplasty, anterior lamellar keratoplasty, deep anterior lamellar keratoplasty, and artificial cornea. The shortage of cornea donors and side effects of artificial corneas bring limitations to these methods. Therefore, novel approaches are needed to overcome these limita- 
tions. Although some research has confirmed the effectiveness of cell-/stem cell-based strategies to regenerate corneal stroma, their inadequate regenerative potential encourages researchers to use scaffolds as the supporting structures. Significant progress has been made in recent years in corneal tissue engineering regarding regenerating damaged corneal stroma or replacing it using natural and/or synthetic biopolymers. Future studies should focus on combining different methods to achieve transparent and well-maintained stromal replacements that will be able to not only host stromal cells, but also re-establish stromal functionality to restore vision.

\section{ORCID iDs}

Hamed Nosrati (i) https://orcid.org/0000-0002-6952-1109 Korosh Ashrafi-Dehkordi (1) https://orcid.org/0000-0001-7105-731X Zohreh Alizadeh (1) https://orcid.org/0000-0003-4490-3204 Samira Sanami (1) https://orcid.org/0000-0002-9647-1506 Mehdi Banitalebi-Dehkordi (10) https://orcid.org/0000-0002-4109-1493

\section{References}

1. Sridhar MS. Anatomy of cornea and ocular surface. Indian J Ophthalmol. 2018;66(2):190-194.

2. Pineda R. World corneal blindness. In: Colby KA, Dana R. Foundations of Corneal Disease. Cham, Switzerland: Springer; 2020:299-305.

3. Gain P, Jullienne R, He Z, et al. Global survey of corneal transplantation and eye banking. JAMA Ophthalmol. 2016;134(2):167-173.

4. Gupta N, Tandon R, Gupta SK, Sreenivas V, Vashist P. Burden of corneal blindness in India. Indian J Community Med. 2013;38(4):198-206.

5. Song X, Xie L, Tan X, et al. A multi-center, cross-sectional study on the burden of infectious keratitis in China. PLoS One. 2014;9(12): e113843.

6. Amouzegar A, Chauhan SK, Dana R. Alloimmunity and tolerance in corneal transplantation. J Immunol. 2016;196(10):3983-3991.

7. Córdoba A, Mejía LF, Mannis MJ, Navas A, Madrigal-Bustamante JA Graue-Hernandez EO. Current global bioethical dilemmas in corneal transplantation. Cornea. 2020;39(4):529-533.

8. Avadhanam VS, Liu CS. A brief review of Boston type-1 and osteoodonto keratoprostheses. Br J Ophthalmol. 2015;99(7):878-887.

9. Riau AK, Mondal D, Yam GH, et al. Surface modification of PMMA to improve adhesion to corneal substitutes in a synthetic core-skirt keratoprosthesis. ACS App/ Mater Interfaces. 2015;7(39):21690-21702.

10. Mobaraki M, Abbasi R, Omidian Vandchali S, Ghaffari M, Moztarzadeh F, Mozafari M. Corneal repair and regeneration: Current concepts and future directions. Front Bioeng Biotechnol. 2019;7:135.

11. Chen Z, You J, Liu X, et al. Biomaterials for corneal bioengineering. Biomed Mater. 2018;13(3):032002.

12. Liu T, Shen M, Huang L, et al. Characterization of hyperelastic mechanical properties for youth corneal anterior central stroma based on collagen fibril crimping constitutive model. J Mech Behav Biomed Mater. 2020;103:103575.

13. Ruberti JW, Roy AS, Roberts CJ. Corneal structure and function. Annu Rev Biomed Eng. 2011;13:269-295.

14. Ethier $C R$, Johnson $M$, Ruberti JW. Ocular biomechanics and biotransport. Annu Rev Biomed Eng. 2004;6:249-273.

15. Khor E, Lim LY. Implantable applications of chitin and chitosan. Biomaterials. 2003;24(13):2339-2349.

16. DelMonte DW, Kim T. Anatomy and physiology of the cornea. J Cataract Refract Surg. 2011;37(3):588-598.

17. Cintron C, Covington $\mathrm{H}$, Kublin CL. Morphogenesis of rabbit corneal stroma. Invest Ophthalmol Vis Sci. 1983;24(5):543-556.

18. Winkler M, Chai D, Kriling S, et al. Nonlinear optical macroscopic assessment of 3-D corneal collagen organization and axial biomechanics. Invest Ophthalmol Vis Sci. 2011;52(12):8818-8827.

19. Shah S, Laiquzzaman MJ. Comparison of corneal biomechanics in pre and post-refractive surgery and keratoconic eyes by Ocular Response Analyser. Cont Lens Anterior Eye. 2009;32(3):129-132.
20. Donohue D, Stoyanov B, McCally R, Farrell RA. Numerical modeling of the cornea's lamellar structure and birefringence properties. J Opt Soc Am A Opt Image Sci Vis. 1995;12(7):1425-1438.

21. Gipson IK, Spurr-Michaud SJ, Tisdale AS. Hemidesmosomes and anchoring fibril collagen appear synchronously during development and wound healing. Dev Biol. 1988;126(2):253-262.

22. Levin LA, Nilsson SF, ver Hoeve J, Wu S, Kaufman PL, Alm A. Adler's Physiology of the Eye E-Book. London, UK: Elsevier Health; 2011.

23. Chan SWS, Yucel Y, Gupta N. New trends in corneal transplants at the University of Toronto. Can J Ophthalmol. 2018;53(6):580-587.

24. Anshu A, Price M, Price F. Risk of corneal transplant rejection significantly reduced with Descemet's membrane endothelial keratoplasty. Ophthalmology. 2012;119(3):536-540.

25. Fontana L, lovieno A, Moramarco A. Anterior lamellar keratoplasty and deep anterior lamellar keratoplasty. In: Eye Banking: Changing Face of Corneal Transplantation. Hauppauge, NY: Nova Science Publishers, Inc; 2015:57-66.

26. Karimian F, Feizi S. Deep anterior lamellar keratoplasty: Indications, surgical techniques and complications. Middle East Afr J Ophthalmol. 2010;17(1):28-37.

27. Bahar I, Kaiserman I, McAllum P, Slomovic A, Rootman D. Comparison of posterior lamellar keratoplasty techniques to penetrating keratoplasty. Ophthalmology. 2008;115(9):1525-1533.

28. Melles $G$, Eggink $F$, Lander $F$, et al. A surgical technique for posterior lamellar keratoplasty. Cornea. 1998;17(6):618-626.

29. Terry MA, Ousley PJ. Deep lamellar endothelial keratoplasty: Visual acuity, astigmatism, and endothelial survival in a large prospective series. Ophthalmology. 2005;112(9):1541-1548.

30. Price FW, Price MO. Descemet's stripping with endothelial keratoplasty in 200 eyes: Early challenges and techniques to enhance donor adherence. J Cataract Refract Surg. 2006;32(3):411-418.

31. De Quengsy GP. Précis ou cours d'opérations sur la chirurgie des yeux: puisé dans le sein de la pratique, \& enrichi de figures en taille-douce. Paris, France: Didot; 1790.

32. Stone W Jr, Herbert E. Experimental study of plastic material as replacement for the cornea: A preliminary report. Am J Ophthalmol. 1953;36(62):168-173.

33. Salvador-Culla B, Kolovou PE. Keratoprosthesis: A review of recent advances in the field. $J$ Funct Biomater. 2016;7(2):13.

34. Nonpassopon M, Niparugs M, Cortina MS. Boston type 1 keratoprosthesis: Updated perspectives. Clin Ophthalmol. 2020;14:1189-1200.

35. Jiraskova N, Rozsival P, Burova M, Kalfertova M. AlphaCor artificial cornea: Clinical outcome. Eye (Lond). 2011;25(9):1138-1146.

36. Tan A, Tan DT, Tan XW, Mehta JS. Osteo-odonto keratoprosthesis: Systematic review of surgical outcomes and complication rates. Ocul Surf. 2012;10(1):15-25.

37. Myung D, Duhamel PE, Cochran JR, Noolandi J, Ta CN, Frank CW. Development of hydrogel-based keratoprostheses: A materials perspective. Biotechnol Prog. 2008;24(3):735-741.

38. Schrage N, Hille K, Cursiefen C. Aktuelle Versorgungsmöglichkeiten mit Keratoprothesen. Ophthalmologe. 2014;111(11):1010-1018.

39. Duncker Gl, Storsberg J, Müller-Lierheim WG. The fully synthetic, bio-coated MIRO ${ }^{\circledR}$ CORNEA UR keratoprosthesis: Development, preclinical testing, and first clinical results. Spektrum der Augenheilkunde. 2014;28(6):250-260.

40. Lee R, Khoueir Z, Tsikata E, Chodosh J, Dohlman CH, Chen TC. Longterm visual outcomes and complications of Boston keratoprosthesis type II implantation. Ophthalmology. 2017;124(1):27-35.

41. Kaur J. Osteo-odonto keratoprosthesis: Innovative dental and ophthalmic blending. J Indian Prosthodont Soc. 2018;18(2):89-95.

42. Schrage N, Hille K, Cursiefen C. Current treatment options with artificial corneas: Boston KPro, Osteo-odontokeratoprosthesis, Miro Cornea $^{\circledR}$ and KeraKlear ${ }^{\mathbb{B}}$ [in German]. Ophthalmologe. 2014;111(11): 1010-1018.

43. Ghaffariyeh A, Honarpisheh N, Karkhaneh A, et al. Fyodorov-Zuev keratoprosthesis implantation: Long-term results in patients with multiple failed corneal grafts. Graefes Arch Clin Exp Ophthalmol. 2011;249(1):93-101.

44. Ma X, Xiang R, Meng X, et al. Russian keratoprosthesis in StevensJohnson syndrome. Cornea. 2017;36(3):304-309.

45. Akpek E, Alkharashi M, Hwang F, Ng S, Lindsley K. Artificial corneas versus donor corneas for repeat corneal transplants. Cochrane Database Syst Rev. 2014;11:CD009561. 
46. Hollick EJ, Watson SL, Dart JKG, Luthert PJ, Allan BDS. Legeais BioKPro III keratoprosthesis implantation: Long term results in seven patients. Br J Ophthalmol. 2006;90(9):1146-1151.

47. MatthyssenS,VandenBogerdB,DhubhghaillSN,KoppenC,ZakariaN. Corneal regeneration: A review of stromal replacements. Acta Biomater. 2018;69:31-41.

48. Kong $B$, Mi S. Electrospun scaffolds for corneal tissue engineering: A review. Materials (Basel). 2016;9(8):614

49. Kilic Bektas C, Hasirci V. Mimicking corneal stroma using keratocyte-loaded photopolymerizable methacrylated gelatin hydrogels. J Tissue Eng Regen Med. 2018;12(4):e1899-e1910.

50. Kim H, Jang J, Park J, et al. Shear-induced alignment of collagen fibrils using 3D cell printing for corneal stroma tissue engineering. Biofabrication. 2019:11(3):035017.

51. Wu J, Du Y, Mann MM, Yang E, Funderburgh JL, Wagner WR. Bioengineering organized, multilamellar human corneal stromal tissue by growth factor supplementation on highly aligned synthetic substrates. Tissue Eng Part A. 2013;19(17-18):2063-2075.

52. Ozcelik B, Brown KD, Blencowe A, Daniell M, Stevens GW, Qiao GG. Ultrathin chitosan-poly (ethylene glycol) hydrogel films for corneal tissue engineering. Acta Biomater. 2013;9(5):6594-6605.

53. Ghezzi CE, Muja N, Marelli B, Nazhat SN. Real time responses of fibroblasts to plastically compressed fibrillar collagen hydrogels. Biomaterials. 2011;32(21):4761-4772.

54. Ahearne M, Wilson SL, Liu K-K, Rauz S, El Haj AJ, Yang Y. Influence of cell and collagen concentration on the cell-matrix mechanical relationship in a corneal stroma wound healing model. Exp Eye Res. 2010;91(5):584-591.

55. Duncan TJ, Tanaka Y, Shi D, Kubota A, Quantock AJ, Nishida KJB Flow-manipulated, crosslinked collagen gels for use as corneal equivalents. Biomaterials. 2010;31(34):8996-9005

56. Kubrak-Kisza M, Kisza KJ, Misiuk-Hojło M. Corneal cross-linking: An example of photoinduced polymerization as a treatment modality in keratoconus. Polim Med. 2016;46(1):89-94.

57. Phu D, Wray LS, Warren RV, Haskell RC, Orwin EJ. Effect of substrate composition and alignment on corneal cell phenotype. Tissue Eng Part A. 2010;17(5-6):799-807.

58. Zhang W, Chen J, Qu M, et al. Sustained release of TPCA-1 from silk fibroin hydrogels preserves keratocyte phenotype and promotes corneal regeneration by inhibiting interleukin- $1 \beta$ signaling. Adv Healthc Mater. 2020;9(17):2000591.

59. San Choi J, Williams JK, Greven M, et al. Bioengineering endothelialized neo-corneas using donor-derived corneal endothelial cells and decellularized corneal stroma. Biomaterials. 2010;31(26):6738-6745.

60. Shang K, Rnjak-Kovacina J, Lin Y, et al. Accelerated in vitro degradation of optically clear low $\beta$-sheet silk films by enzyme-mediated pretreatment. JAMA Ophthalmol. 2013;131(5):676.

61. Lawrence BD, Marchant JK, Pindrus MA, Omenetto FG, Kaplan DL. Silk film biomaterials for cornea tissue engineering. Biomaterials. 2009;30(7):1299-1308.

62. Rahimipour S, Salahinejad E, Sharifi E, Nosrati H, Tayebi L. Structure, wettability, corrosion and biocompatibility of nitinol treated by alkaline hydrothermal and hydrophobic functionalization for cardiovascular applications. Applied Surface Science. 2020;506:144657.

63. Zafari M, Aghajani S, Mansouri Boroujeni M, Nosrati H. Vancomycinloaded electrospun polycaprolactone/nano-hydroxyapatite membrane for the treatment of blood infections. Med Hypotheses. 2020; 144:109992.

64. Ma A, Zhao B, Bentley AJ, et al. Corneal epithelialisation on surface-modified hydrogel implants. J Mater Sci Mater Med. 2011;22(3): 663-670.

65. Gil ES, Mandal BB, Park S-H, Marchant JK, Omenetto FG, Kaplan DL. Helicoidal multi-lamellar features of RGD-functionalized silk biomaterials for corneal tissue engineering. Biomaterials. 2010;31(34): 8953-8963.

66. Lai J-Y, Li Y-T, Cho C-H, Yu T-C. Nanoscale modification of porous gelatin scaffolds with chondroitin sulfate for corneal stromal tissue engineering. Int J Nanomedicine. 2012;7:1101-1114.
67. Orash Mahmoud Salehi A, Nourbakhsh MS, Rafienia M, BaradaranRafii A, Heidari Keshel S. Corneal stromal regeneration by hybrid oriented poly ( $\varepsilon$-caprolactone)/lyophilized silk fibroin electrospun scaffold. Int J Biol Macromol. 2020;161:377-388.

68. Fernández-Pérez J, Kador KE, Lynch AP, Ahearne M. Characterization of extracellular matrix modified poly( $\varepsilon$-caprolactone) electrospun scaffolds with differing fiber orientations for corneal stroma regeneration. Mater Sci Eng C. 2020;108:110415.

69. Lai JY. Corneal stromal cell growth on gelatin/chondroitin sulfate scaffolds modified at different NHS/EDC molar ratios. Int J Mol Sci. 2013;14(1):2036-2055.

70. Kong B, Chen $\mathrm{Y}$, Liu R, et al. Fiber reinforced GelMA hydrogel to induce the regeneration of corneal stroma. Nat Commun. 2020;11(1): 1435.

71. Wang S, Ghezzi CE, White JD, Kaplan DL. Coculture of dorsal root ganglion neurons and differentiated human corneal stromal stem cells on silk-based scaffolds. J Biomed Mater Res A. 2015;103(10): 3339-3348.

72. Ghezzi CE, Wang L, Behlau I, et al. Degradation of silk films in multipocket corneal stromal rabbit models. J Appl Biomater Funct Mater. 2016;14(3):e266-e276.

73. Gosselin EA, Torregrosa T, Ghezzi CE, et al. Multi-layered silk film coculture system for human corneal epithelial and stromal stem cells. J Tissue Eng Regen Med. 2018;12(1):285-295.

74. Cui Z, Zeng Q, Liu S, et al. Cell-laden and orthogonal-multilayer tissue-engineered corneal stroma induced by a mechanical collagen microenvironment and transplantation in a rabbit model. Acta Biomater. 2018;75:183-199.

75. Hu X, Lui W, Cui L, Wang M, Cao Y. Tissue engineering of nearly transparent corneal stroma. Tissue Eng. 2005;11(11-12):1710-1717.

76. Ghezzi CE, Marelli B, Omenetto FG, Funderburgh JL, Kaplan DL. 3D functional corneal stromal tissue equivalent based on corneal stromal stem cells and multi-layered silk film architecture. PLoS One. 2017;12(1):e0169504.

77. Luo L-J, Lai J-Y, Chou S-F, Hsueh Y-J, Ma DH-K. Development of gelatin/ascorbic acid cryogels for potential use in corneal stromal tissue engineering. Acta Biomater. 2018;65:123-136.

78. Wu J, Du Y, Mann MM, Funderburgh JL, Wagner WR. Corneal stromal stem cells versus corneal fibroblasts in generating structurally appropriate corneal stromal tissue. Exp Eye Res. 2014;120:71-81.

79. Syed-Picard FN, Du Y, Lathrop KL, Mann MM, Funderburgh ML, Funderburgh JL. Dental pulp stem cells: A new cellular resource for corneal stromal regeneration. Stem Cells Trans/ Med. 2015;4(3):276-285.

80. Chou SF, Lee CH, Lai JY. Bioengineered keratocyte spheroids fabricated on chitosan coatings enhance tissue repair in a rabbit corneal stromal defect model. J Tissue Eng Regen Med. 2018;12(2):316-320.

81. Lee HJ, Fernandes-Cunha GM, Na KS, Hull SM, Myung D. Bio-orthogonally crosslinked, in situ forming corneal stromal tissue substitute. Adv Healthc Mater. 2018:e1800560. doi:10.1002/adhm. 201800560

82. de la Cruz Cardona J, lonescu A-M, Gómez-Sotomayor R, et al. Transparency in a fibrin and fibrin-agarose corneal stroma substitute generated by tissue engineering. Cornea. 2011;30(12):1428-1435.

83. Torbet J, Malbouyres M, Builles N, et al. Orthogonal scaffold of magnetically aligned collagen lamellae for corneal stroma reconstruction. Biomaterials. 2007;28(29):4268-4276.

84. Guan L, Ge H, Tang X, et al. Use of a silk fibroin-chitosan scaffold to construct a tissue-engineered corneal stroma. Cells Tissues Organs. 2013;198(3):190-197.

85. Shimmura S, Doillon CJ, Griffith M, et al. Collagen-poly (n-isopropylacrylamide)-based membranes for corneal stroma scaffolds. Cornea. 2003;22(7 Suppl 1):S81-S88.

86. Bektas CK, Hasirci V. Cell incorporated methacrylated gelatin (GelMA) hydrogels for corneal stroma tissue engineering. Conference abstract (poster). 10 $0^{\text {th }}$ World Biomaterials Congress, Montréal, Canada, 17 May-22 May, 2016. doi:10.3389/conf.FBIOE.2016.01.02297 